\title{
Crítica ensaística e resistência política em Jean-Claude Bernardet: o caso Lição de Amor
}

\author{
Margarida Maria Adamatti
}

Resumo: Nos anos 1970, Jean-Claude Bernardet escrevia no jornal Opinião (1972-1977), periódico ligado à resistência ao regime militar. Compondo artigos referenciais sobre o cinema brasileiro, ele dava continuidade ao seu trabalho de crítica participativa, intervindo politicamente no campo do cinema. Analisamos alguns traços do pensamento cinematográfico de JeanClaude Bernardet na imprensa alternativa, tomando como exemplo a crítica publicada sobre Lição de amor (1975) de Eduardo Escorel.

Palavras-chave: Jean-Claude Bernardet; imprensa alternativa; jornal Opinião; crítica de cinema; crítica de intervenção; Cinema Novo.

Abstract: Critique essays and political resistance by Jean-Claude Bernardet: the case of Lesson of Love - In the 1970s, Jean-Claude Bernardet wrote for the newspaper Opinion (1972-1977), which was linked to the resistance to the military regime. Writing referential articles about Brazilian cinema, he continued his work of participatory critique, intervening politically in the field of cinema. We examine some of the traits of Jean-Claude Bernardet's cinematographic thinking in the underground press, taking as example the critique published about the Lesson of Love (1975) by Eduardo Escorel.

Keywords: Jean-Claude Bernardet; underground press; Opinião newspaper; film critique; intervention critique; New Cinema.

Até meados dos anos 1950, o belga de nascimento Jean-Claude Bernardet permanecia mergulhado na cultura francesa em pleno Brasil. Falava pouco o português e vivia num ambiente seleto do ponto de vista cultural. A inserção na cultura brasileira e a convivência com críticos e futuros cinemanovistas tem início quando ele entra para o Cineclube Dom Vital. 
Trabalhando na Cinemateca Brasileira, ele recebe o convite para fazer parte da equipe que cobriria as férias de Paulo Emilio Salles Gomes no Suplemento Literário do jornal O Estado de S. Paulo.

Repensando constantemente seu ato crítico, Jean-Claude Bernardet faz parte dos críticos que reformulavam sua postura em relação ao cinema brasileiro no início dos anos 1960. Na I Convenção Nacional da Crítica Cinematográfica em 1960, boa parte dos críticos pensava sua função como uma forma de intervenção necessária para o sucesso do cinema nacional. Uma dessas formulações marcou a década. Durante a Convenção, Paulo Emilio Salles Gomes apresenta a tese Uma situação colonial? (Gomes, 1981, p. 286-291). O artigo altera de maneira definitiva a forma de pensar o cinema brasileiro. Especificadamente sobre a crítica, Paulo Emilio mostrava como a situação de subdesenvolvimento econômico do cinema atingia o olhar do crítico sobre a produção local. Ele tomava as obras nacionais como inferiores, desprezando o cinema brasileiro por suas características incipientes.

Inserido nesse contexto e alinhado ao pensamento do mestre Paulo Emilio Salles Gomes, Bernardet repensava a função de sua crítica no mesmo período (Cf. BERNARDET, 1978). Segundo ele, cabia ao crítico participar da produção e circulação de ideias. Assim nasceu, nele, a vontade de realizar uma crítica de intervenção com a possibilidade de influenciar o campo cinematográfico, que só seria possível se o objeto de estudo fosse o cinema brasileiro. Bernardet relaciona esse momento de sua constituição crítica com a eclosão do Cinema Novo, que exigia do crítico uma postura participativa, num período de grande efervescência cultural. Essa nova crítica defende um cinema de perspectiva política que revela e transforma a realidade brasileira (Cf. Bernardet, 1979). A crítica era vista como uma ferramenta de mudanças sociais, e o crítico-intelectual queria participar do processo de modificação da realidade.

Da solicitação de uma atitude ativa em relação ao cinema brasileiro, institui-se a defesa da crítica participativa. Não era somente a crítica que deveria ser participativa, mas o intelectual, ${ }^{1}$ num conceito caro não só ao campo do cinema, mas presente, por exemplo, na obra de Antonio Candido. O crítico quer dialogar com o contexto brasileiro para modificá-lo. Essa atitude nasce do sentimento de missão diante da necessidade de alterar a realidade.

Antonio Candido observa a mesma alteração na atitude do intelectual, passando da passividade à participação no artigo Literatura e Subdesenvolvimento. ${ }^{2}$ O pressuposto é de ruptura na consciência do intelectual. A etapa da consciência amena do atraso caracteriza boa parte da história de nossa intelectualidade, que não possuía uma atitude participativa em relação à cultura. O progresso ainda parecia uma solução acertada ao país.

1 A discussão sobre a crítica participativa diz respeito também ao papel do intelectual. Estava em discussão no período a noção de intelectual engajado. Ver Em defesa dos intelectuais de Sartre (1994).

2 Revista Argumento. n. 1, out. 1973. 
Excluindo-se da relação com o povo, a intelligentsia construía para si uma posição deformada diante da cultura. O que desejava era fazer desaparecer a incultura popular para a realização do progresso. Como consequência, o intelectual passou a considerarse como grupo flutuante, à parte da sociedade. A exclusão do contexto fez com que a intelectualidade brasileira tomasse como ponto de referência o elemento estrangeiro. Sem encarar-se criticamente, ela se dissociou de sua terra.

Após os anos 1950, parte da intelectualidade mudou de postura, embora alguns permanecessem na fase anterior, acreditando nas possibilidades grandiosas do país. Estes mantinham uma perspectiva pessimista, vendo a cópia e dependência como fator de alienação. Os que saíram da postura passiva, já na fase da consciência catastrófica do atraso, avançaram na questão, dirigindo-se à luta e à reformulação política. O subdesenvolvimento não é mais visto como fator condicionante, mas acarreta numa ação propulsora, que dá novo empenho aos intelectuais. Quanto mais o homem se convence da "realidade trágica do subdesenvolvimento", mais ele "se imbui da aspiração revolucionária", do desejo de promover alterações nas estruturas internas (CANDIDO, 2006, p. 186).

Esse era um dos ideais do período: o crítico ou intelectual como agente social que contribuía para o fortalecimento da democracia, transformando a sociedade. As alterações da visão do crítico e do intelectual descritas acima, juntamente com a conjuntura política do país, são fundamentais para pensar a trajetória desenvolvida por Jean-Claude Bernardet dali em diante. O próprio Bernardet (2011) esclarece que estava interessado em problematizar a ação do intelectual, procurando linhas ideológicas das obras através da análise da linguagem, em busca dos níveis menos perceptíveis ou menos intencionais do filme. A preocupação principal é com o papel que o cineasta desempenha na sociedade e como esse papel revela-se nos filmes. Assim ele escreve textos dirigidos aos próprios intelectuais e cineastas para explicar seu relacionamento com a sociedade de que falam.

Um exemplo dessa preocupação, na crítica de Bernardet, encontra-se no artigo sobre Lição de Amor de Eduardo Escorel, que analisamos aqui. O texto é citado pelo crítico como um dos melhores exemplos de seu trabalho na imprensa alternativa. ${ }^{3}$ Além disso, o artigo permite compreender a complexidade da sua forma de escrita a partir do conceito de estrutura, que é uma das chaves de seu pensamento. Embora Bernardet seja referência obrigatória no campo de cinema, o estudo de sua obra enquanto crítico está para ser feito. ${ }^{4}$ Dada a extensão de trabalhos possíveis, escolhemos o jornal alternativo Opinião, que congrega várias matrizes de seu pensamento nos anos 1970. Nesse semanário, ele publicou inúmeras análises de filmes que se tornaram referências aos pesquisadores.

Se Opinião é síntese entre crítica de cinema e resistência política, uma primeira marca do que Bernardet faria na imprensa alternativa estaria ainda no jornal Última Hora entre 1963-1964.

3 Pasta AJCB PI-1-18 da Cinemateca Brasileira.

4 A referência para analisar a crítica de cinema de Bernardet é seu livro Trajetória Crítica (1978). Informações gerais: Mourão (2007), Souza (2002) e Magno (1999). 
Ali ele desenvolveu a crítica conteudística (Cf. Bernardet, 1978), voltada aos lançamentos em salas populares, para um público popular. O objetivo era revelar aos leitores presos ao enredo o processo de construção do filme, desvendando seu discurso e contradições. Indiretamente essa crítica pretendia auxiliar no desenvolvimento analítico do espectador perante os filmes, conscientizando o público. Dessa postura deriva um tipo de crítica praticada depois em Opinião: são artigos de fácil leitura, amparados pelo entendimento sociológico do filme e de sua representação da sociedade, cujo objetivo é explicar a produção dentro do contexto político brasileiro.

Não era por preferência pessoal que Jean-Claude Bernardet usava a crítica de conteúdo, mas por necessidade ou falta de melhor opção. No posfácio do livro A significação no cinema de Christian Metz, Bernadet (in METZ, 1972) comenta que a matriz do pensamento da crítica brasileira é de conteúdo. Ele opõe-se a essa metodologia por sua incapacidade de atingir o específico cinematográfico. A mesma insuficiência vale para a crítica sociológica; ela consegue discorrer sobre tudo que fala o filme, menos sobre o filme. Por causa da falta de acesso à película na sala de montagem, Bernardet declara que teve de recorrer à crítica de conteúdo no livro Brasil em tempo de cinema. Essa atrelada à crítica sociológica, em 1972, ainda parecia o melhor método disponível: ela "ainda dá bons frutos mas parece chegar ao final de suas possibilidades". Em seus escritos, Bernardet continuamente procurou um método para escrever suas críticas. Realizando diversas autorreflexões sobre seu trabalho, ele comentava a falta de critério metodológico para realizar a crítica: "Não encontrei até agora um método de trabalho que me satisfaça e que possa revelar ao máximo os filmes dos quais falo" ${ }^{\prime 2}$.

Revendo seu trabalho no jornal Última Hora, Bernardet (2011) expõe sua tentativa de se aproximar de uma crítica cinematográfica "popular" ao analisar a ideologia da produção comercial importada. Porém o público-alvo desses filmes não tinha o hábito de ler crítica de cinema, e quem lia a crítica da Última Hora não assistia a esse tipo de produção. O mesmo processo ocorreu nos artigos da imprensa alternativa, de acordo com ele. A linha desses jornais também era conteudística, mas as seções culturais ainda eram vistas como amenidades. Os textos mais complexos tiveram alguma repercussão, mas provavelmente não eram lidos pelo público.

A crítica de Última Hora tornou-se uma crítica de ruptura na medida em que o Golpe Militar, de 31 de março de 1964, deu fim a todo o trabalho desenvolvido por Bernardet, tanto no jornal, quanto na Cinemateca Brasileira. Com a instauração do regime militar, o crítico enfrentou muitas dificuldades. Ele era professor da Universidade de Brasília, quando ela foi fechada pelos militares em 1965. Bernardet estava com a dissertação pronta e foi impedido de defendê-la; o mestrado só foi publicado em 1967, transformando-se no livro Brasil em tempo de cinema. Um novo enfrentamento ocorreu quando ele foi aposentado pelo regime militar do cargo de professor da Universidade de São Paulo,

5 Acervo Jean-Claude Bernardet. Cinemateca Brasileira. Declaração do autor. s.d. 
em 1969, em decorrência do Ato Institucional Número 5. Sem poder ministrar cursos de longa duração na Escola de Comunicações e Artes, Bernardet passou por dificuldades financeiras. Exercia a crítica na imprensa, fazia palestras e seminários, ministrava cursos de extensão em outras faculdades. Muitas vezes tinha de escrever com pseudônimos, como Carlos Murao no jornal Opinião entre 1973-1974.

No contexto de enfrentamento ao regime militar, a participação de Bernardet na imprensa alternativa fazia parte da resistência. Como jornal de oposição ao regime, Opinião (1972-1977) foi fortemente censurado; metade de suas 230 edições foi vetada. Trata-se do jornal alternativo de base política mais importante da imprensa alternativa (Cf. Kucinski, 1991).

$\mathrm{Na}$ área de cinema, Opinião congregou importantes críticos, como Jean-Claude Bernardet, Sérgio Augusto, Gustavo Dahl. O jornal costumava examinar os filmes pelo fator político. Tratava-se de uma crítica de esquerda com conteúdo inovador, que não se furtava a debater e pensar o cinema brasileiro em cartaz. Jornal nacionalista por excelência defendia a ocupação do cinema brasileiro contra a hegemonia hollywoodiana, mas tinha uma postura dual diante do Estado; visto como carrasco e protetor do cinema brasileiro.

Em Opinião, Bernardet desenvolve uma crítica militante, defendendo o cinema nacional pelo local de origem. Por esse motivo, ele assistia a todos os filmes brasileiros em cartaz. Da atitude de intervenção sobre a realidade, o crítico continuava a defender filmes que falassem sobre a sociedade brasileira, como fez na época do surgimento do Cinema Novo.

O tom geral dos artigos de Bernardet em Opinião é ensaístico, longe da mais comum pretensão de objetividade jornalística. Há uma tonalidade confessional, jamais autoritária, que não se furta a provocar um debate.

Muito longe de querer traçar uma tipologia da crítica de Jean-Claude Bernardet, procuramos fornecer neste artigo um olhar sobre algumas matrizes de sua crítica que incidem no artigo sobre Lição de Amor. As características acima descritas de crítica participativa, sociológica e conteudística serão acrescidas ainda da intersecção entre a análise estética e política.

\section{A adaptação dos clássicos da literatura e a política cinematográfica: o caso Lição de amor}

Durante os anos 1970, o regime militar incentivava a produção de adaptações literárias através de financiamentos e prêmios como uma maneira de dar algum tipo de orientação temática à produção nacional. Necessitando de recursos para filmar, muitos cineastas aceitaram entrar na onda da adaptação de clássicos da literatura, sem que isso significasse uma cooperação com os planos do Estado. Ao utilizar o formato das adaptações literárias ou do filme histórico, os diretores aproveitavam a brecha para realizar filmes críticos e cifrados sobre o momento político. Nesse período, Eduardo Escorel era conhecido como o montador dos filmes do Cinema Novo. 
Em 1975, Escorel lança seu primeiro longa-metragem, Lição de amor, uma adaptação do romance Amar, verbo intransitivo, de Mário de Andrade, que narra o envolvimento amoroso entre Carlos e Fräulein, a governanta alemã contratada para realizar a iniciação sexual do jovem a pedido do pai rico. A expectativa da crítica de cinema era grande por causa do histórico cinemanovista do diretor.

Se nos anos 1970, os diretores do Cinema Novo buscaram desenvolver uma linguagem brasileira para dar conta de revelar a miséria do país, não só no conteúdo, mas também na forma, o debate toma outros rumos em meados da década. Acusados de hermetismo e de utilizar uma linguagem autoral incompreensível ao povo, os veteranos do movimento buscaram o contato com o público, conscientes da necessidade de dialogar com o mercado. ${ }^{6}$ Nesse novo viés, Escorel opta em seu primeiro longa-metragem pela linguagem clássica como possibilidade de contato com o público. ${ }^{7}$

O artigo "Uma estética bem comportada?" (BERNARDET, 1976) expõe algumas características marcantes da escrita de Bernardet. O texto é escrito num movimento oscilante, quase pendular. E são exatamente essas nuances da forma que conferem um dinamismo interno. Por motivos didáticos, separamos os principais argumentos em blocos para ressaltar suas oposições, mas procuramos manter a ordem geral de apresentação do texto original.

O artigo é escrito na primeira pessoa, como de costume. Inicia-se com um resumo da saudação da crítica de cinema a Escorel, porque Lição de amor conquistou prêmios e público, trazendo uma solução ao cinema brasileiro:

Festejado com flores e pássaros metálicos, Lição de amor é um filme providencial. Ele se apresenta como a solução do impasse em que muitos veem enfiada a produção cinematográfica brasileira, encurralada que estaria a vulgaridade popularesca das porno-chanchadas, e o perigo político que representariam filmes como aqueles produzidos na década de 60 pelo Cinema Novo.

Em seguida, Bernardet entra no quesito político. Ele evidencia como Lição de amor dialoga com a sugestão do governo de adaptar clássicos da literatura para o cinema:

O governo vem há anos desenvolvendo uma política cultural que leva os cineastas a se voltar para os clássicos literários. (...) Esta política pode não ter dado até agora resultados considerados relevantes. Mas Lição de amor, com seu sucesso de crítica e de público, prova que ela pode dar bons frutos. Ou seja: pode resultar em obras que deem a uma certa burguesia brasileira uma lisonjeira imagem de si mesma.

Ao citar no início do texto o perigo político do Cinema Novo, o segundo parágrafo indica a tendência de fuga do cinema político para a adaptação literária, sem explicitar

6 Sobre as mudanças do Cinema Novo em 1970, ver Xavier (2001). Sobre filme histórico e a política cinematográfica, ver Bernardet (1979-1980).

7 Johnson (JOHNSON e STAM, 1982) vê uma postura dual em Lição de amor. Escorel abre mão da autorreflexão do romance, mas o filme é mais ambíguo e sutil do que o livro. 
com todas as letras a tentativa de orientação estatal. O autor toma cuidado com as palavras: o governo desenvolve uma política cultural que leva os cineastas a se voltar para os clássicos literários. Os verbos "desenvolver", "levar" e "voltar-se-á" atenuam o sentido do direcionamento estatal. Indiretamente fica claro que o governo não beneficia obras políticas. O trecho coloca em evidência que a estrutura externa (leia-se condições políticas) interfere na temática do filme. O excerto não pára por aí, estabelecendo uma ligação entre o objetivo do Estado e o sucesso de público e de crítica que Lição de amor colocou em prática. Mais do que isso, nesse caso, houve uma conformidade entre a orientação estatal e o conteúdo do filme, criando uma visão lisonjeira da burguesia.

O segundo parágrafo será concluído só com a última parte do artigo, compondo um retrato circular de argumentação. Bernardet deixa implícito nessas primeiras linhas, mas só conclui com todas as letras no final do texto que, sem dinheiro, os cineastas rendem-se ao projeto do governo de realizar adaptações de clássicos da literatura como tentativa de contenção de temas políticos. No entanto, o parágrafo possibilita uma segunda leitura: existe uma estratégia de negar-se enquanto cinema político por causa do regime militar. É sobre esse percurso que Bernardet irá falar.

A continuação do artigo prova com a análise do enredo como o filme possui uma imagem lisonjeira da burguesia. Lição de amor traz uma visão positiva dos "avós" burgueses:

Os burgueses do filme não são assim tão desmerecedores. É claro que eles são criticados: tudo é mercadoria para eles e os sentimentos do filho são manipulados como qualquer negócio que se faz para dar lucros. (...) O casal Souza Costa é visto com ironia, sem dúvida, mas também e principalmente com a ternura condescendente que se teria ao folhear um álbum de fotografias de avós ultrapassados e um pouco ridículos, mas a quem no fundo se quer bem. Eles fornecem uma imagem digna dos avós da burguesia brasileira.

O casal Souza Costa possui uma casa ampla e elegante, veste-se bem, tem bons modos, dá uma sensação de segurança e estabilidade: o casal Souza Costa dá dos avós da atual burguesia brasileira uma imagem digna. Estamos longe do retrato "incompetente" e involuntariamente grotesco que às vezes a chanchada faz dos grã-finos. (...)

Mas estamos longe, e como! da ironia e do retrato quase burlesco que Mário de Andrade faz dos Souza Costa.

Até os parágrafos iniciais sobre o conteúdo ou sobre a apresentação da burguesia, a análise não vê uma contestação política. O artigo segue assim num movimento de espiral, adentrando em camadas de análise cada vez mais densas e reflexivas. Da discussão sobre o conteúdo lisonjeiro sobre os burgueses, Bernardet chega ao estudo da forma em dois trechos separados, que acompanham esse mesmo movimento de espiral. No primeiro trecho inicial, a forma é prova de qualidade; ao mesmo tempo ela não problematiza o presente. O segundo excerto no final do artigo é bem mais complexo: 
A feitura extremamente cuidada do trabalho, a sua harmonia e homogeneidade, a lógica imperturbável da construção dramática, abordando problemas "eternos" enfiados num passado que não corre o risco de arranhar o presente, sob os auspícios justificadores de um monumento literário: não é um ideal? Os bem pensantes podem extrair satisfação tanto ao nível da realização do filme, quanto daquilo que ele mostra.

E me pergunto se o estilo do filme, até mesmo o estilo de Eduardo Escorel (...) não tentaria responder a estas contradições e ambiguidades. O estilo do diretor é olímpico. A rigorosa racionalidade em todos os momentos de elaboração do filme, o perfeccionismo, que não excluem delicadeza, instauram um nível de expressão contido, sempre aquém da emoção tanto da dele como da dos personagens. Um olhar, a contração de um músculo facial são o suficiente, no estilo de Escorel (...) para sugerir grandes sentimentos. Essa polidez, esse recato, essa altivez com que Escorel elabora sua expressão dão certa densidade aos sentimentos não exteriorizados, mas são também uma maneira aristocrática de não entrar no mérito do assunto, é pairar acima das contradições.

Há uma sutil diferença entre os dois trechos descritos acima. Saindo de uma leitura mais externa do filme como prova de qualidade no primeiro excerto, o final do artigo explica Escorel na entrelinha. Sua forma de pairar acima das contradições indica exatamente a riqueza do filme, que não pode avançar totalmente na problematização sobre a relação do cineasta com o Estado. Sua maneira aristocrática é parte dessa contradição e ambiguidade. Não se trata simplesmente de cooptação de Escorel, como poderia parecer nos primeiros parágrafos, mas de uma cumplicidade que envolve muitas contradições.

Dando continuidade ao estudo sobre a forma do filme, o artigo insere Lição de amor na discussão do uso da linguagem clássica pela qual o Cinema Novo optava no final dos anos 1960. Bernardet condena essa mesma linguagem por não realçar os mecanismos ideológicos, isto é, a linguagem clássica não gera reflexão no espectador. Sua preferência é pelo cinema moderno que se revela enquanto discurso ${ }^{8}$. Por esses motivos, Bernardet vê o filme como um retrocesso:

Sem pensar que o filme pudesse retomar o mesmo questionamento do romance, pode-se notar que o romance indaga (até certo ponto) o seu instrumental, enquanto que o filme, não. O filme não questiona, diante do espectador o instrumental cinematográfico de que se vale. É indiscutivelmente o retrocesso do filme em relação ao romance do ponto de vista crítico.

Para provar sua teoria, o crítico traz trechos do livro em que Mário de Andrade indaga seu próprio aparato instrumental, questionando a forma do romance. Havia uma inquietação,

8 Essa condenação à linguagem clássica do cinema pretendia desmascarar a ideologia por detrás da produção. Ela estava em pauta, por exemplo, na revista Cahiers du Cinéma a partir de 1968, que prefere o cinema moderno. Ver Baecque (2010) e Xavier (2001). 
uma reflexão sobre a narrativa, inexistente no filme. Escorel não questiona seu instrumental cinematográfico; usa recursos narrativos para criar uma ilusão, como se assistíssemos a um pedaço da realidade. O diretor não revela ao espectador que se trata de ilusão narrativa, daí o sentimento de retrocesso. A condenação à linguagem clássica tem dois motivos: ela oculta os mecanismos de produção, e principalmente não coloca em questão a relação com o Estado. Assim a forma impecável da produção e a construção favorável aos burgueses no conteúdo cabem perfeitamente no projeto governamental.

Se no início, o autor frisava mais a estrutura externa, leia-se política cinematográfica, como detonador da forma e do conteúdo, os parágrafos finais desconstroem a argumentação do próprio texto. Num movimento pendular, Bernardet defende uma afirmação, para em seguida negá-la, e depois voltar ao ponto inicial. Eis alguns dos contra-argumentos lançados no final do artigo:

Fräulein como projeção de um certo tipo de intelectual. Um desses intelectuais imprensados entre o projeto cultural e a remuneração é o diretor do filme. Como nos serviços prestados por Fräulein à família burguesa Souza Costa, a realização de Lição de amor supõe contradição, ambiguidade e cumplicidade entre o projeto cultural e a prestação de serviço.

Uma opção teria sido denunciar esta dimensão do filme, apresentar esta dimensão como geradora do filme (inserir no filme a revelação do processo de produção de que é fruto). O que fazia estourar personagens, linguagem ilusória, e então denunciava a prestação de serviços, portanto deixava de prestar serviços. Outra opção era deixar latente esta dimensão, um suave filigrana: assim não se poderia dizer que esta dimensão não estava no filme, mas sem que ela chegue a alterar o papel social que o filme está desempenhando. Tudo leva a crer que é esta última opção que foi perfeita [grifo nosso].

O cineasta que descreveu o envolvimento emocional de Fräulein e que a fez repetir com tanta insistência que ela queria seus oito contos, não está absolutamente alheio nem às contradições da governanta, nem às próprias.

Os trechos acima recortados desviam os comentários sobre a forma e a representação da burguesia para incidir na composição da personagem de Fräulein. Bernardet demonstra que a maneira encontrada para contradizer a política cinematográfica em Lição de amor não estava na forma do cinema moderno. Não, a atitude do diretor foi mais sutil. Escorel trabalhou com filigranas. Por esse motivo a contestação foi feita na construção de Fräulein, isto é, nas relações sociais construídas pela personagem. Sem utilizar a linguagem moderna para questionar os mecanismos cinematográficos, a discordância foi ainda mais tênue. Quando Bernardet declara: "tudo leva a crer que é esta última opção que foi perfeita", a frase indica o quanto o comentário político estava dissimulado em Fräulein. A partir dessa personagem, a análise do filme atinge o diretor.

O comentário final encerra a argumentação do início do artigo. Ao apelo de adaptação literária, solicitado pelo governo, Escorel acaba por aceitar seus oito contos, 
como Fräulein. Teve de render-se à forma aprovada pelo Estado para poder produzir cinema, mas contestou a orientação na entrelinha através da composição de Fräulein. Os dois trechos não são só indicativos da relação de Escorel com o Estado autoritário, mas problematizam também as relações dos cineastas com o mesmo Estado na figura de Fräulein. O debate vai muito além de Escorel; diz respeito também à aproximação entre cinemanovistas e política cultural. A forma do texto reproduz em sua organização o movimento contraditório e complexo dessa relação.

Também esses contra-argumentos são sucedidos de uma ou duas críticas negativas ao filme, num enorme quebra-cabeças destinado ao leitor. A linguagem cifrada serve para evitar dar informações aos censores; serve para transmitir sentidos políticos que seriam censurados num texto totalmente transparente e direto.

Não é só para evitar a interdição que o artigo é escrito dessa maneira. A forma ensaística de Bernardet em Opinião foge de uma argumentação de autoridade. Num movimento de hesitação, em tom dialético, a argumentação torna-se muito mais complexa. É como se ele escrevesse duas críticas antagônicas no mesmo artigo. Parece uma marca recorrente do estilo dele afirmar algo para sugerir depois outra possibilidade de leitura, numa obra aberta. Parece também uma forma de ensinar aos leitores a refletir, sem aceitar argumentos prontos.

Por último, mas não menos importante, a crítica a Lição de amor não aborda somente os preceitos de crítica sociológica, conteudística e participativa já descritos. $\mathrm{Na}$ intersecção entre estética e política, encontramos a forma de análise que estrutura todo o movimento em espiral do texto: ele não é nada mais do que o próprio conceito de estrutura (Cf. CANDIDO, 2011).

Bernardet poderia ter utilizado somente a crítica sociológica, como às vezes ocorria em Opinião. É legítimo que se faça uma análise apenas do elemento externo, como na sociologia; mas quando a ênfase recai somente na dimensão social, corre-se o risco de esquecer o fator estético. Por esse motivo o estudo de base sociológica se mostrava uma ferramenta incompleta. A análise de Jean-Claude Bernardet sobre Lição de amor consegue tocar a complexidade entre a estrutura interna e o contexto social.

Sem separar o estudo da forma do contexto repressivo, Bernardet enfrentou suas conexões. Ele não analisou a obra por si mesma; caso tivesse feito isso, pensaria o estilo de Escorel como detonador único de sua estrutura interna. Estaria somente ao lado da crítica à obra de arte pura, fora do contexto. Ao contrário, a dimensão social e o estilo não podem ser desconectados, porque os fatores externos e sociais são agentes da estrutura interna, de tal forma que a realidade social se transforma em componentes da estrutura cinematográfica.

Como aplicar o conceito de estrutura para explicar Lição de amor? A política cinematográfica do regime autoritário (estrutura externa) foi agente da forma (estrutura interna) do filme, afinal de contas essa política levou Escorel a ter de recorrer à adaptação literária para conseguir financiamento. Contudo esse fator não explica a obra por completo. O financiamento não significou adesão ao regime autoritário, nem uma visão apologética 
do passado; porque a forma do filme tem autonomia em relação à estrutura externa. Esta última pode influir ou não na mise en scène, talvez ela tenha se feito presente na adequação à adaptação literária por causa da censura.

Do estilo de Escorel, analisado por Bernardet, apreende-se a singularidade da obra; e nessa singularidade o elemento social foi filtrado na concepção estética do autor; não obrigatoriamente do regime. Porém, a estrutura externa pode ter sido em parte responsável por Escorel ter colocado as críticas ao sistema no conteúdo do filme, através de Fräulein, e não na forma. Por outro lado, essa opção pode também significar a preferência do diretor pela linguagem clássica. Temos de levar em conta outro fator: a defesa do cinema clássico significava para os egressos do Cinema Novo uma forma política de conquistar o público através de uma linguagem convencional. Novamente teríamos uma influência do fator externo sob a mise en scène.

O movimento do artigo passa pelas duas formulações ao ver Lição de amor como síntese da política cinematográfica e da resistência. Como vemos, a relação entre todos esses fatores não fecha uma equação simples de resolver. Assim a forma de escrita de Bernardet revela ao mesmo tempo a complexidade do conceito de estrutura e as ambiguidades na aproximação com o Estado. Forma e contexto estão tão imbricados que é impossível determinar fronteiras claras entre o projeto político e a criação autoral.

Quando o crítico articula num todo complexo a forma e estrutura interna de Lição de amor com o contexto da política cinematográfica, ele vai além de uma crítica sociológica; caminha em direção a uma crítica integral, que segundo Antonio Candido não deve desconectar os aspectos formais dos aspectos sociais. Afinal nenhuma obra se explica por si só:

(...) saímos dos aspectos periféricos da sociologia, ou da história sociologicamente orientada, para chegar a uma interpretação estética que assimilou a dimensão social como fator de arte. Quando isto se dá, ocorre o paradoxo assinalado inicialmente: o externo se torna interno e a crítica deixa de ser sociológica, para ser apenas crítica. (...) Neste nível de análise, em que a estrutura constitui o ponto de referência, as divisões pouco importam, pois tudo se transforma, para o crítico, em fermento orgânico de que resultou a diversidade coesa do todo. (CANDIDO, 2011, p. 17)

O artigo revela que Bernardet, em Opinião, não tratava o cinema apenas pelo viés político, como uma forma de subordinação da arte. Fugia, portanto, da crítica sociológica determinista. Ao contrário, estética e política completam-se, porque uma é fator de composição da outra. A análise a Lição de amor indica o quanto Bernardet desconstruiu, aglutinou e reelaborou diversas matrizes da crítica de cinema em sua trajetória em Opinião. Por fim, num trecho de Trajetória Crítica, Bernardet explica como articula uma análise mais profunda, através do conceito de estrutura: "É necessário atingir a sua estrutura e 
pesquisar a significação da estrutura enquanto tal e não enquanto veículo de conteúdo." (BERNARDET, 1978, p. 231).

Na aplicação desse conceito à Lição de amor, vemos o quanto o crítico não só deflagra as significações imediatas do filme, mas vai além desse estudo mais explícito, porque sozinho ele não daria conta nem de revelar a ligação com o presente, nem de compreender a imagem sobre a sociedade dos anos 1920. Quando o estudo incide sobre o conteúdo estético, não só sobre o conteúdo do filme, a análise vai além de explicar as intenções da obra e de Escorel.

Para tanto, ele não exclui nenhum tipo de metodologia, numa proposta parecida com a da crítica integral de Antonio Candido. Atento à análise do filme em detalhes, Bernardet foge da crítica sociológica que vê a obra como ilustração dos conflitos sociais. Dessa forma, o crítico preserva o fator estético através do estudo concreto do filme para investigar como o estético trabalha historicamente. Bernardet quer demonstrar como se dá a resistência cultural de Lição de amor no campo estético, ao invés de procurar as formas estéticas dos conflitos sociais, como a crítica mais terrena costumava fazer.

Margarida Maria Adamatti é doutoranda no Programa Meios e Processos Audiovisuais da ECA/USP.

mmadamatti@hotmail.com

\section{Referências}

BAECQUE, A. Cinefilia - invenção de um olhar, história de uma cultura 1944-1968. São Paulo: Cosac\&Naify, 2010.

BERNARDET, J. C. Uma estética bem comportada? Opinião, Rio de Janeiro, n. 194, p. 32, 23 jul. 1976. Trajetória Crítica. São Paulo: Polis, 1978.

. Cinema Brasileiro: propostas para uma história. Rio de Janeiro: Paz e Terra, 1079.

. (org.). Anos setenta: cinema. Rio de Janeiro: Europa: 1979-1980.

Brasil em tempo de cinema. São Paulo: Cia das Letras, 2007.

. Resistência e Rebeldia. In MELO, J. M. de. Pensamento comunicacional uspiano - impasses mundializadores na Escola de Comunicações e Artes (1973-2011). São Paulo: ECA/USP, 2011, p. 51-53. v. 2.

CANDIDO, A. A educação pela noite. Rio de Janeiro: Ouro sob Azul, 2006.

Literatura e sociedade. Rio de Janeiro: Ouro sobre Azul, 2011.

GOMES, P. E. S. Uma situação colonial? In: Crítica de cinema no Suplemento Literário. Rio de Janeiro: Paz e Terra, 1981. v. 2. 
JOHNSON, R., STAM, R. Brazilian Cinema. Londres/Toronto: Associated University Presses, 1982.

KUCINSKI, B. Jornalistas e revolucionários - nos tempos da imprensa alternativa. São Paulo: Página Aberta, 1991.

MAGNO, M. Na alquimia das imagens. 1999.

METZ, C. A significação no cinema. São Paulo: Perspectiva, 1972.

MOURÃO, D. Jean-Claude Bernardet: uma homenagem. São Paulo: Imprensa Oficial/Cinemateca Brasileira, 2007.

SARTRE, Jean-Paul. Em defesa dos intelectuais. São Paulo: Ática, 1994.

SOUZA, J. I. Paulo Emilio no Paraíso. Rio de Janeiro: Record, 2002.

XAVIER, I. Cinema brasileiro moderno. São Paulo: Paz e Terra, 2001.

Artigo recebido em julho e aprovado em novembro de 2013. 